\title{
Design for Social Change: \\ Harnessing the Student Voice to Prevent Sexual Assault and Sexual Harassment
}

\author{
Kate Elton \\ Bridget Malcolm \\ Catharine Pruscino \\ Domenic Svejkar \\ University of Technology Sydney
}

\begin{abstract}
Respect.Now.Always. is an Australia-wide campaign to address and eliminate sexual assault and harassment within universities. The University of Technology Sydney (UTS) has taken a proactive stance and established a Student Consultative Group and a Senior Working Group to address this issue. UTS Design Innovation Research Centre (DIRC) was engaged to understand diverse UTS student perspectives on sexual violence and identify student-centred opportunities for prevention and support. Using a participatory design research approach, DIRC developed insights on UTS student experiences in interacting with UTS. Rather than being simple user-centred research interactions, these engagements reframed the interaction with students as participatory experiences where they were given an opportunity to engage in two-way dialogue, which strengthened relationships within the UTS community and provided an opportunity for perspectives to shift on this topic. This unique design research approach was made possible through careful work establishing trust with senior stakeholders, and leads the way for more novel activations to engage the community in preventing sexual assault and harassment.
\end{abstract}

\section{Introduction}

In 2016, UTS joined the other Australian universities to launch the Respect.Now.Always. campaign to ensure that students and staff are safe from sexual assault and sexual harassment. As part of this work, the Australian Human Rights Commission (AHRC) conducted a national survey of more than 30,000 students, to better understand the prevalence of this issue and the extent of underreporting. The AHRC survey found the issue of sexual assault and harassment to be broad-reaching for a number of university cohorts, with many unexplored dimensions including factors such as sexual harassment on public transport to and from university, awareness of available support services within universities, the issue of better understanding, addressing and responding to perpetrators, and the specific experiences of certain cohort groups where particularly little is known (for example, post graduate students).

In response to the survey results, Universities Australia released a '10-Point Plan' including a 1800 support phone line and training programs. UTS has commenced its own set of preliminary initiatives, the most significant being the establishment of a senior working group to develop and implement changes through a number of different work streams. While the Respect.Now.Always. campaign has been received positively as a significant step forward to address the prevention of sexual assault and harassment, it has not been without criticism. An End Rape on Campus (EROC) report (2017) is particularly critical of some previous efforts by other universities whose rush to implement changes has resulted in initiatives which are perceived by the student cohort as insensitive and over simplistic. This sentiment has also been echoed in the media backlash following the release of other online training programs across the sector.

UTS' work on sexual assault and harassment comes at an interesting time when this issue has been brought into the public domain through high-profile cases such as those in the entertainment industry in Australia and internationally. These events have promoted public campaigns (\#metoo and \#timesup), which have not only revealed the prevalence of sexual assault and harassment in our society, but also the complexities of this issue, such as determining what constitutes sexual harassment, the impact of reporting and the perpetrator perspective. Importantly, emerging public stories of these previously hidden events is beginning to lessen the taboo of talking 
about sexual assault and harassment, a trend which has been supported by other well-known campaigns such as the 'Tea and Consent' video.

Within a university context, efforts have included encouraging open dialogue to help understand the issue of sexual assault and harassment and increased acceptance for victims to seek support. Community building has shown to be a strong element of university initiatives, including a notable example at Deakin university where staff and students were invited to display their experiences and thoughts about sexual assault and harassment visibly on clothes lines around the university campuses.

\section{Using a design approach}

Design as a practice has been evolving from the design of visual and material objects through to the design of services and the design of solutions to complex problems (van der Bijl-Brouwer and Dorst 2017). It is being adopted as a powerful approach to address complex issues, including social challenges, and as such is being increasingly applied within the public and social sectors (Bason 2014). Human-centred design is a key design approach for working with social challenges and applies principles and methods to understand human beings and their interaction with their environment (van der Bijl-Brouwer and Dorst 2017). The growing reputation of the potential of human-centred design led the Respect.Now.Always. Project Lead, enabled by the Provost, to engage with UTS' own Design Innovation Research Centre to help understand the deeper qualitative elements of student experience and expectations that go beyond what can be obtained in a survey. The case study below describes the outcomes of this project with the RNA Project Lead and DIRC, some reflections on the student-university partnerships and the power of design approaches for complex social issues.

\section{Case study: Harnessing the student voice to prevent sexual assault and harassment}

From the beginning of UTS' response to the Respect.Now.Always campaign, students were invited to nominate two representatives to sit as permanent members of the Working Group through the Student's Association. There was still the challenge however, of how we were going to ensure that students would be at the centre of our program more generally. As a result, we explored how could we amplify the UTS Student Voice, to ensure that our response to the Respect.Now.Always. campaign, as well as the growth of our community was genuinely informed by UTS' student needs.

\section{Governance}

The presence of sexual assault and sexual harassment on university campuses is a global issue that has traditionally been managed by university administration in accordance with the university rules within their legal jurisdictions. At the request of the Australia's 39 universities, the Australian Human Rights Commission conducted a national survey of tertiary students. The subsequent Change the Course report (AHRC 2017) provided greater insight into the nature, prevalence and reporting of sexual assault and sexual harassment at Australian universities. The survey also examined the effectiveness of university services and policies designed to address sexual assault and sexual harassment on campus and found that ninety-four percent (94\%) of students who were sexually harassed and eight-seven percent $(87 \%)$ of students who were sexually assaulted did not make a formal report or complaint to their university.

Aside from statutory rules and sanctions at play in the broader criminal justice system, universities have largely relied on academic misconduct rules, embodied in their governing constitutions, as the source of power to deter and deal with the sexual assault and sexual harassment. What is apparent from the body of findings from the AHRC report is that the governance mechanisms that have typically been available to universities have not been sufficient to adequately address sexual assault and sexual harassment. 
Within UTS, the Vice-Chancellor and President, Professor Brungs established a senior Working Group led by the Provost and Senior Vice-President, Professor Parfitt, that included senior managers from across the University's administration and student representatives with support from a dedicated Project Lead. This group has carriage of the University's program of work in relation to Respect.Now.Always. and works collaboratively to align UTS' operational objectives of commitment to zero tolerance. Included in the program's governance structure is the Student Consultative Group (SCG). The membership of the SCG reflects the diversity of the UTS' student population. The role of the SCG is to work collaboratively with the senior Working Group to support the stewardship for the prevention of sexual assault and sexual harassment in our community and guide our student-informed change program. The students meet bi-monthly, and their role is to identify, question, provide input and review the program.

Also reporting to the Working Group, is our Student Voice work stream led by DIRC, a transdisciplinary centre that provides niche expertise in the integration of design-led methodologies and tools with traditional business practice.

\section{Research approach and process}

The focus of DIRC's research efforts was to understand, from the student perspective, the UTS student experience, and the UTS systems (services, programs etc.) that they interact with, in the context of sexual assault and sexual harassment. The research undertaken was qualitative, and designed to generate deep insights from across the UTS community, to support the quantitative AHRC survey findings. This was based on research methods derived from applied ethnography and participatory design, comprising:

- A brief literature review to gain a baseline understanding of sexual assault and harassment on university campuses

- Semi-structured interviews with current UTS students to gain in-depth perspectives on student experiences and interactions with the UTS system

- Participatory design research engagements with staff and governance forums including the Sexual Assault and Harassment Working Group, the Student Consultative Group and the Senior Manager's Forum to explore research findings and drive further lines of inquiry

- Participatory design research engagements to gain input from commencing and continuing students

Key elements of the research are described below.

\section{Semi-structured interviews with current UTS students}

The semi-structured interviews were held with twelve (12) UTS students who were interested in sharing their experiences or perspectives about interacting with UTS in the context of sexual assault or sexual harassment. The intention of this phase of the research was to gain in-depth perspectives on student experiences and interactions with the UTS system. These interviews included visual prompts of university services and (hypothetical) prototyped concepts to encourage students to think about how they are currently supported by UTS, compared to how they would prefer to be supported. The interviews uncovered rich descriptions of experiences, preferences and attitudes. This information was summarised into eight key insights, a student characteristics diagram, five personas and journeys and a system-map diagram. 


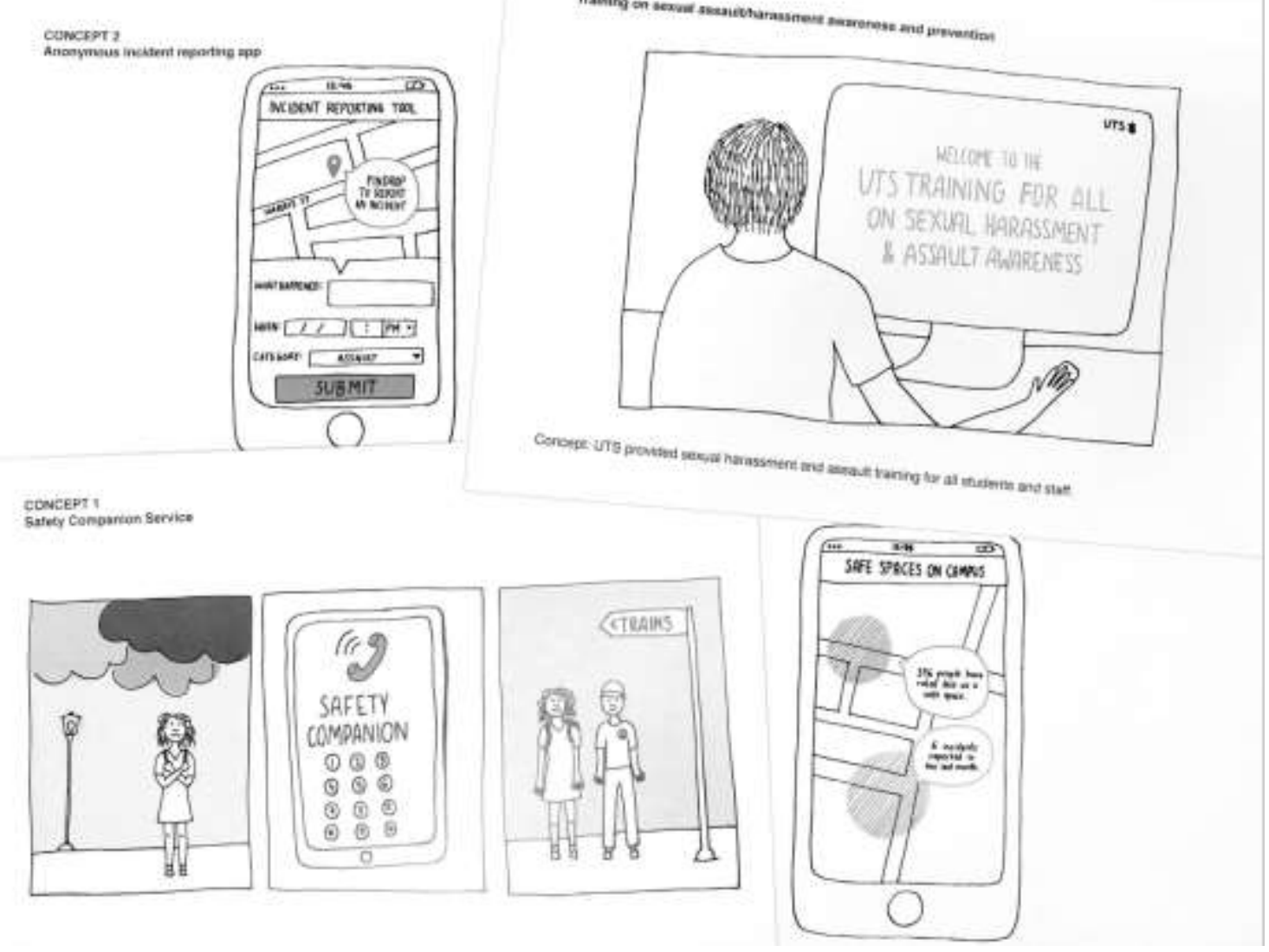

Visual prompts of university services and (hypothetical) prototyped concepts to support student interviews

Stakeholder workshop (participatory design research engagement with the Sexual Assault and Harassment Working Group and Student Consultative Group)

Key stakeholders comprising the Preventing Sexual Assault Working Group, Student Consultative Group and additional university representatives were brought together in a workshop to explore initial research insights generated from the semi-structured interviews.

This session commenced with an introduction into the research design (including targeted cohorts, methodology and approach). Participants were then introduced to the key insights generated from the research. In mixed groups, participants rotated through each individual insight, engaging in dialogue with each other to provide feedback, comments and questions about these insights.

The participants were then introduced to personas - representations of student cohorts - that were engaged during the research. Working in table groups, the participants explored each persona to understand their unique needs and requirements as well as potential solutions that could be generated to meet the needs of these individual personas. The workshop concluded with a rapid generation of remaining 'burning questions' that could be used to inform further research and student engagement. 


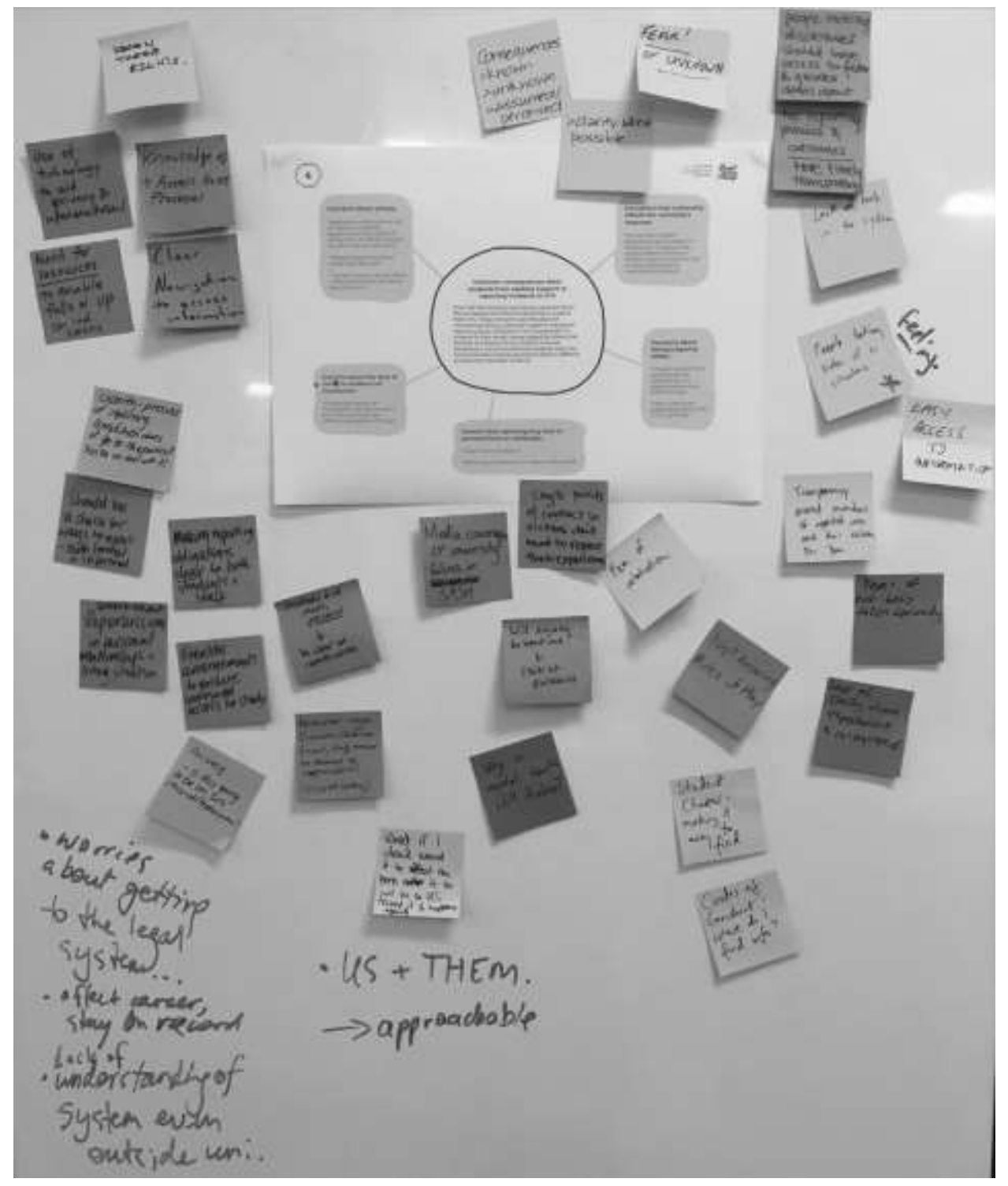

Stakeholder comments made after exploring one of the Student Voice insights

\section{Student participatory design research engagements}

An important part of the research was to test and explore the Student Voice project findings with new and existing students around campus, over four engagements occurring during the student orientation period. While the primary purpose of the engagaments was to collect additional research insights, they also provided an opportunity to share the Respect.Now.Always. campaign with students and inform them about the support services available to them.

The engagements used the 'burning questions' from the stakeholder workshop to develop lines of inquiry. These questions informed the development of interactive question boards and also formed lines of inquiry for one-on-one conversations with students. Findings from each engagement informed the lines of inquiry for the subsequent engagements. These engagements also displayed earlier research findings on colourful posters, including student personas and journeys.

Branding for the campaign was developed with an ice-cream theme and the tag-line "Wanna Spoon? Ask First". This was informed by interview insights that found students desired more opportunities to discuss what is often a taboo social topic in an approachable and normalised way. The engagements all gave away free ice-cream and merchandise developed for the UTS Respect.Now.Always. campaign. 

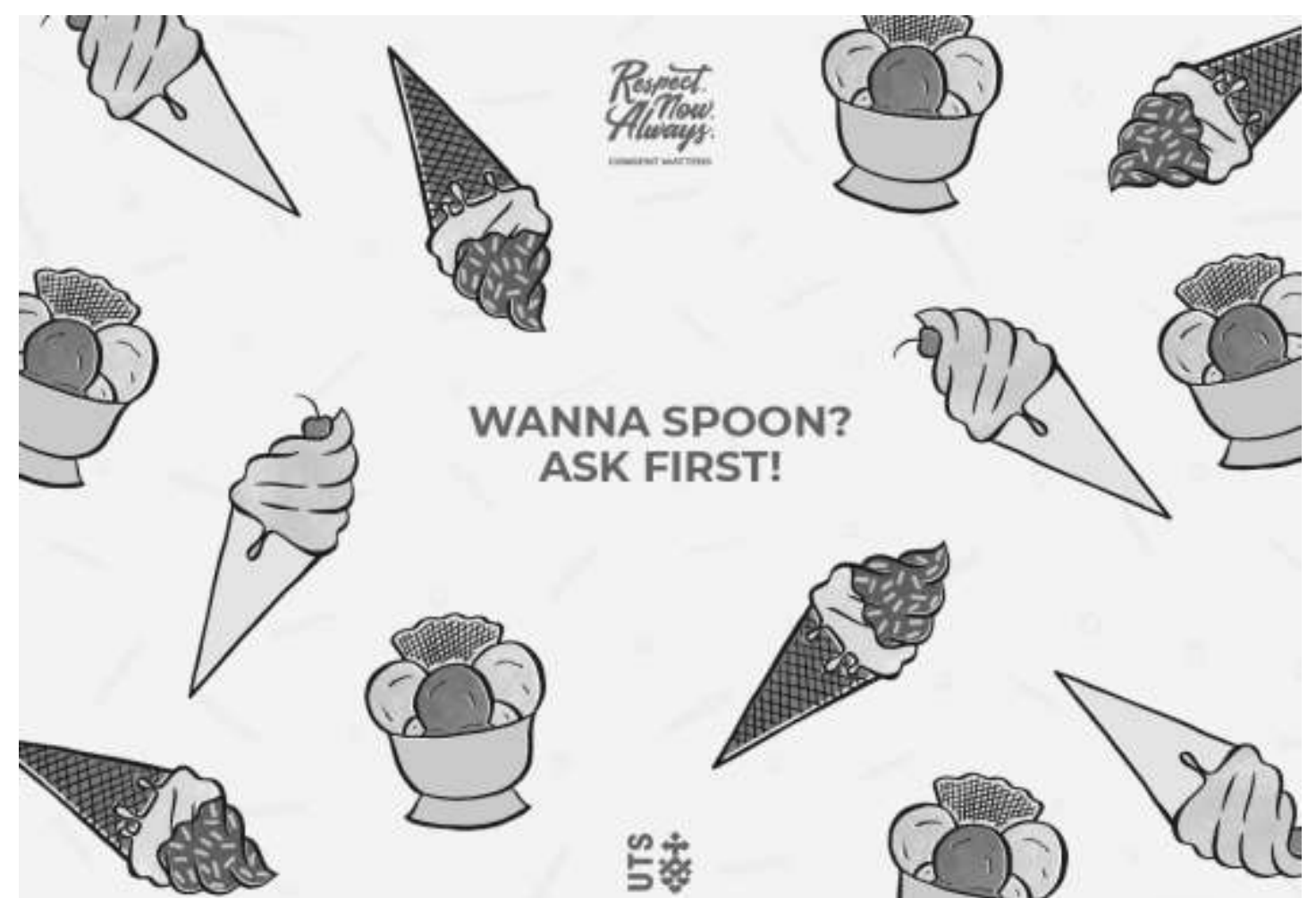

\section{WANNA SPOON? ASK FIRST!}
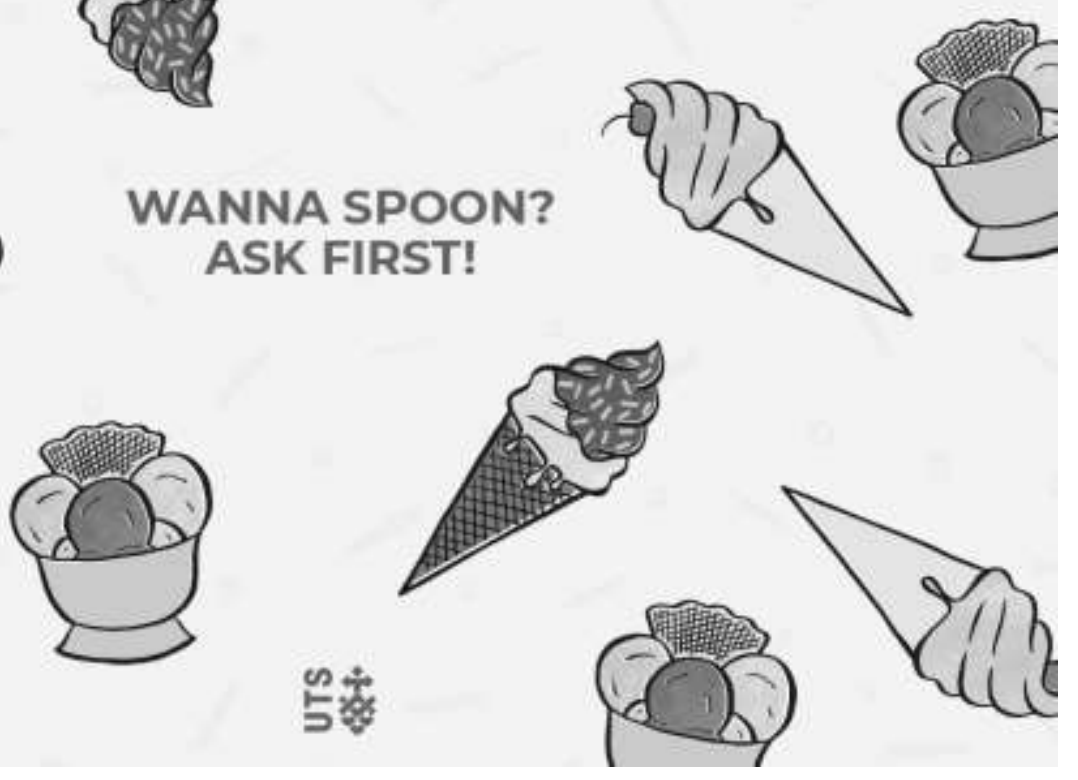

'Wanna Spoon? Ask First!' branding for the campaign and student engagements

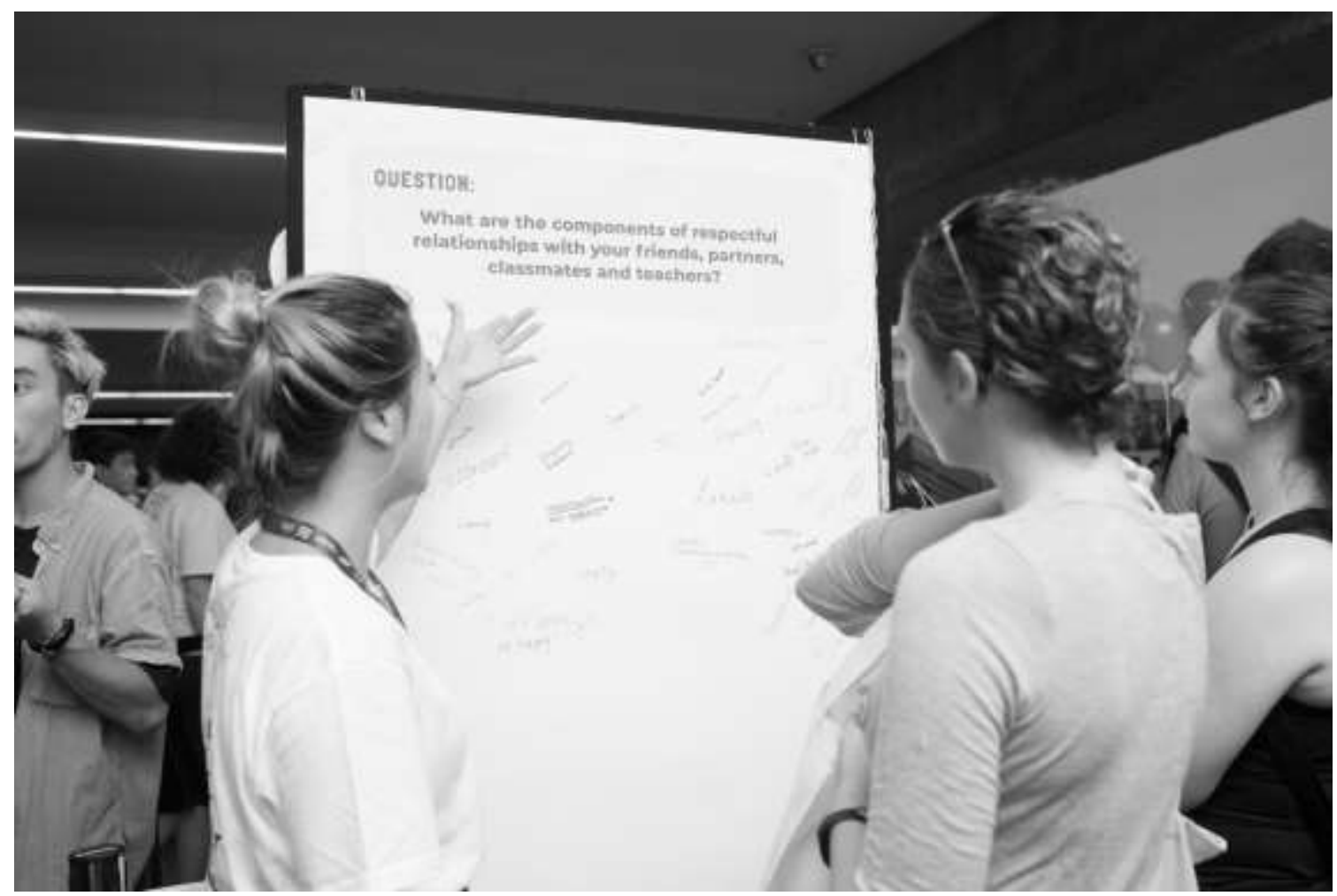

Staff volunteer speaking to students at the O-Day ice cream stall

\section{Commencing students - O-Day}

The first opportunity to engage with commencing students was at O-Day on in March 2018. A physical space was designed and constructed to display the research materials in the foyer of the prominent UTS Tower Building, amongst other stalls promoting clubs and societies. The event received an overwhelmingly positive response, with large queues to enter the space throughout the 
full day and 1300 students attending. Importantly, the event provided a safe and approachable way for staff-volunteers and students to have rich conversations about consent and UTS' role in preventing sexual assault and harassment.

\section{Commencing students - Summerfest}

Following the popularity of the O-Day engagement, the DIRC team were invited to hold the stall at the Activate Summerfest later in the student orientation period. This opportunity allowed engagement with another cohort of commencing students, many of whom had attended the stall at O-Day and had begun to feel a sense of ownership for the Respect.Now.Always. campaign. This included students who volunteered to help engage others in the research questions and to be involved in the campaign going forward. Three hundred and fifty (350) students participated in this engagement and several students commented that it was great to have an opportunity to engage with this topic in a positive and light way, alongside other UTS events such as a music festival.

\section{Continuing students - Tower foyer and Night Owl Noodle Market}

Building on our findings from earlier engagements, we ran another student engagement in April 2018, this time targeted towards continuing students. We ran the stall in two sessions - one during the day in the UTS Tower Foyer, and one in the evening alongside the Student Association's Night Owl Noodle Bar attracting one thousand, one hundred and forty (1140) students altogether. The event at the UTS Tower Foyer aimed to attract students who were moving between classes and who may have been less engaged in the campaign, compared to students who attended a UTS event like Summerfest. The event at the Night Noodle Bar aimed to better understand the perspectives of the culturally diverse international student population who were known to be attendees at this event. Again, we received an overly positive response to the student engagement. One of the important elements of this event was being able to increase the participation of student volunteers. These volunteers collected research responses with us during the engagements and helped in the data synthesis, enabling them to take ownership of the topic and ask questions they personally felt needed to be addressed.

\section{Senior managers forum}

We were invited to share our research and engage one hundred and fifty (150) of the most senior university staff at the Senior Manager's Forum on 29 March 2018. We used this opportunity to run a rapid activity with those present to explore how we might help translate our research insights into meaningful actions that staff could apply to their own specific faculties and areas in a day-to-day context. We focussed on what we had learned in our research about casual academic staff being regularly at the frontline of student interaction and their lack of readiness to respond to student disclosures. The event provided an opportunity to ask staff how they could better support their casual academics in navigating the system before or after a disclosure of sexual assault or harassment.

There was a strong and enthusiastic response from the staff present, and it was promising that a lot of the data reflected similar concerns and desires previously heard from students. For example, a desire to continue the conversation about preventing sexual assault and harassment at UTS and an idea to use scenarios or role play to better understand the complex facets of the problem. A number of staff have come forward since the event asking how they can further be involved in the campaign, including representatives from clubs and societies, internships, sports, physiotherapy, and engineering.

\section{Key insights, findings and implications for the University as a result of the research activities}

Collectively, the research produced a large amount of data that was synthesised and presented in a number of different ways. This included: 
- 21 insights overall (with 8 key initial insights from the semi-structured interviews, as well as further insights across the spectrum of participatory design events)

- 5 student personas

- 5 student journeys

- A student characteristics map

- A UTS systems map

- Feedback and reflections on the insights, personas and journeys during the student-staff workshop

- Burning questions from the student-staff workshop participants

- Answers to the question boards during the participatory ice cream stall events - both qualitative and quantitative data

The insights were developed as a result of a clustering and synthesis process conducted by DIRC. The full list of insights is as follows:

\section{Initial insights from semi-structured interviews:}

1. Many students accept sexual harassment as part of their everyday experience

2. Students are seeking a better understanding of appropriate behaviour

3. Students experience complex internal processing about whether to seek support

4. Unknown consequences deter students from seeking support or reporting incidents to UTS

5. Students prefer informal support processes with people they trust

6. Students need clarity on what support services do

7. Students desire a more open conversation about sexual assault and sexual harassment in the UTS community

8. There is a disconnect in UTS' information on sexual assault and sexual harassment and how this was perceived

\section{Insights from engagements with commencing students:}

9. High-engagement from student driven, interactive campaign

10. Step-change from educational experiences at high school

11. Mixed response to zero-tolerance wording

12. The word 'consent' is not understood by some international students

\section{Insights from engagements with continuing students:}

13. Apprehension and lack of understanding about the purpose of consent matters training

14. Students desire more evolution in the engagement around consent including seeing the impact of their contribution.

15. There is a broad range of diversity in the conversation around consent

16. There is still a need to engage and reach disengaged students and faculties

\section{Insights from staff engagement at the Senior Managers Forum:}

17. There is a desire from staff to have greater staff-student engagement in the topic 
18. A risk-management approach may not create change

19. There is a perception that taking action to prevent sexual assault and harassment will require additional time and resources

20. Staff need more of a 'licence' to act as informal support for others

21. A balance of activities is needed to practically address the issue

\section{Personas and journeys}

Personas and journeys are design tools that we have used to help build empathy for student cohorts and their experiences of the university context. They convey characteristics and attitudes that influence the way different students interact with the UTS system around the issue of sexual assault and sexual harassment. Personas are fictional characters directly based on the research conducted. Personas and journeys help stakeholders and decision-makers to understand the people for whom they are designing and implementing solutions.

In research projects and design initiatives, personas also help us to:

- Convey insights from the interviews into relatable stories

- Fictionally test how different kinds of students might respond to solution ideas

- Create engagement around the choices individuals make when experiencing sexual assault or sexual harassment

- Help students feel they are heard in a way that is confidential and safe.

\section{Meet Misha}
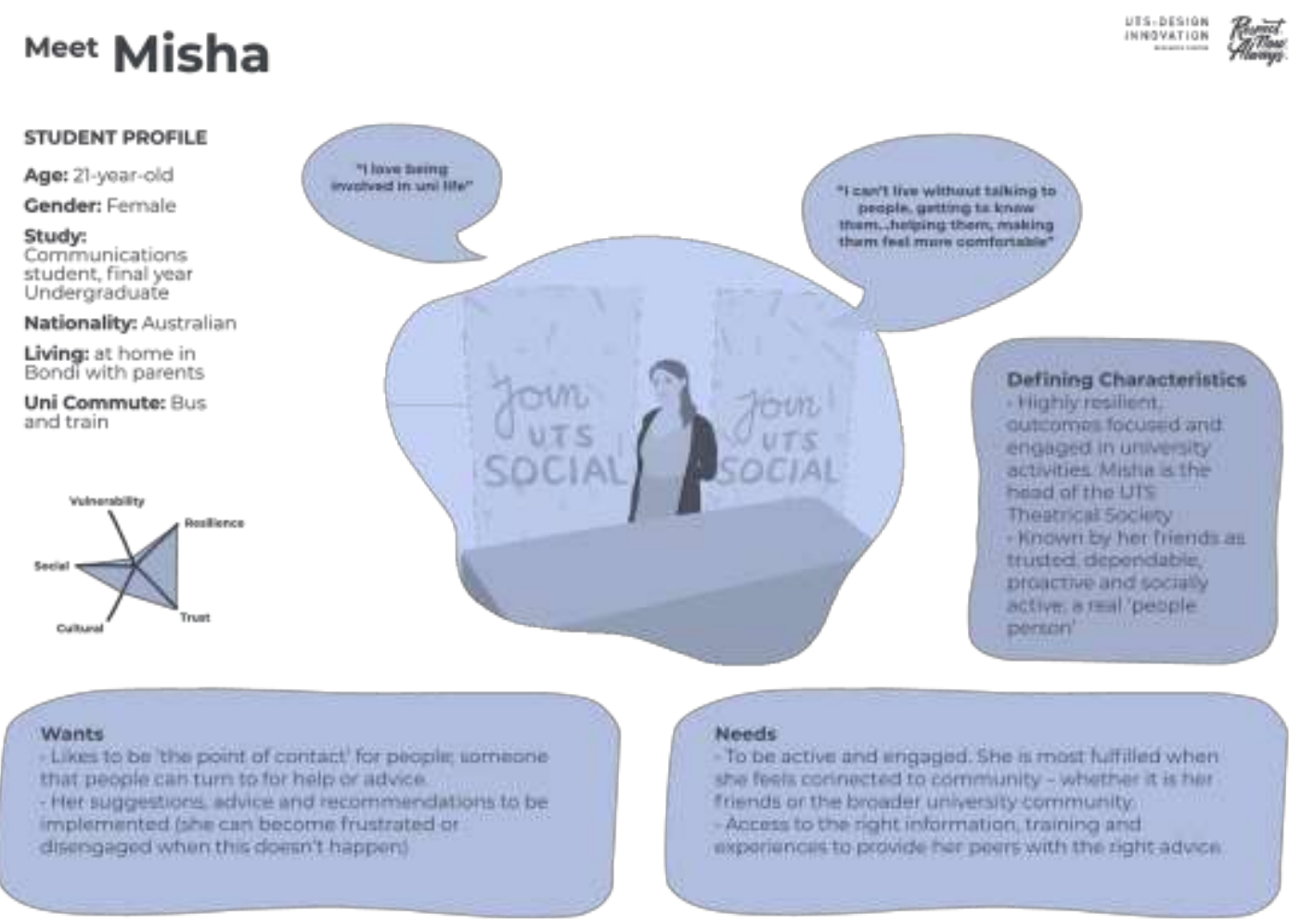

An example of one of the personas created as a result of the initial research via semi-structured interviews. 


\section{()}

Misha's Journey - student supporter to a friend who experienced sexual harassment
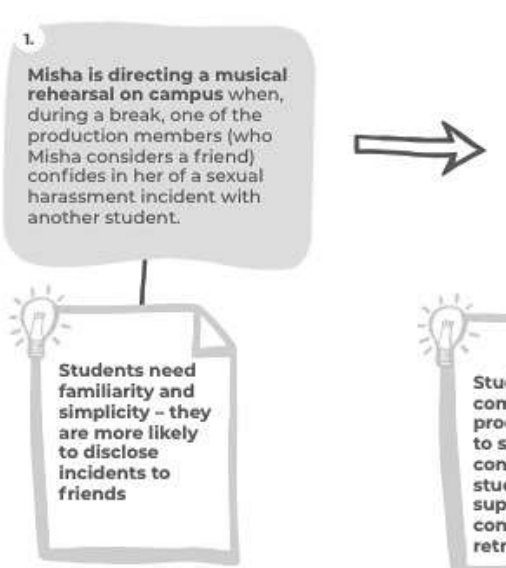

Misha is empathetic, urging him to act and report it but is where to report to. The friend is not compelled by this approach.

"Tt takes time to make change about a problem. Firs: you have to understand it for decide if and when you want to share (2)
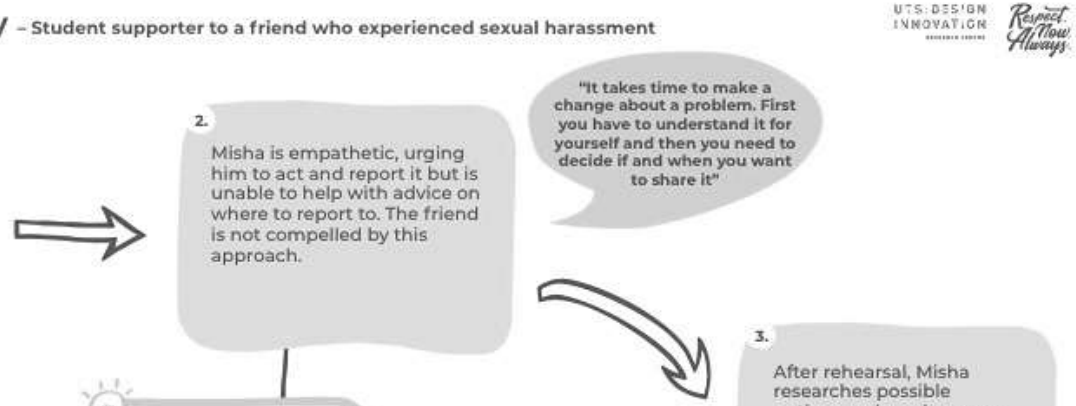

After rehearsal, Mish researches possible options on her phone on 作 inds the counselling Students experience complex internal processing about whether to seek support. Unknown consequences also deter students from seeking concerns about privac retribution and judgment.
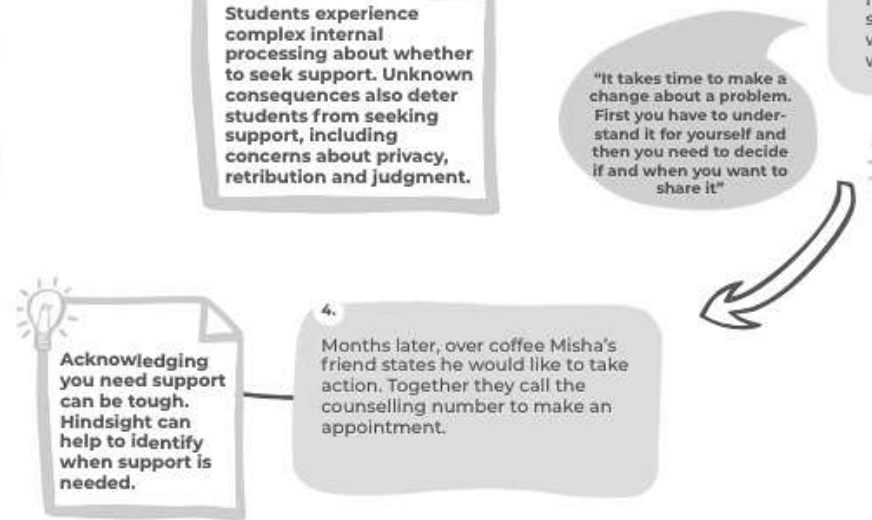
mant about not wanting action.

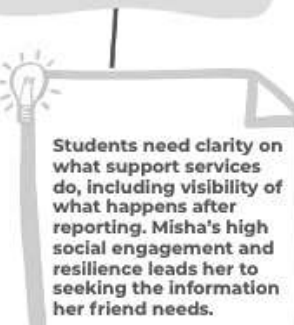

An example of one of the persona journeys created as a result of the initial research via semi-structured interviews.

\section{Questions asked at student engagements}

As mentioned previously, the engagement events used the 'burning questions' from the studentstaff workshop to develop lines of inquiry for the research events. From these 'burning questions', interactive question boards were created that were positive and engaging as well as asking questions in one-on-one conversations with students. Findings from the earlier engagements informed the lines of inquiry for the subsequent events. Questions asked included:

- What would make you feel safe and comfortable seeking support from UTS?

- What are the components of respectful relationships?

- What comes to mind when you hear the word consent?

- What is the weirdest thing you've experienced in Australian social culture? What could help you understand this better? 


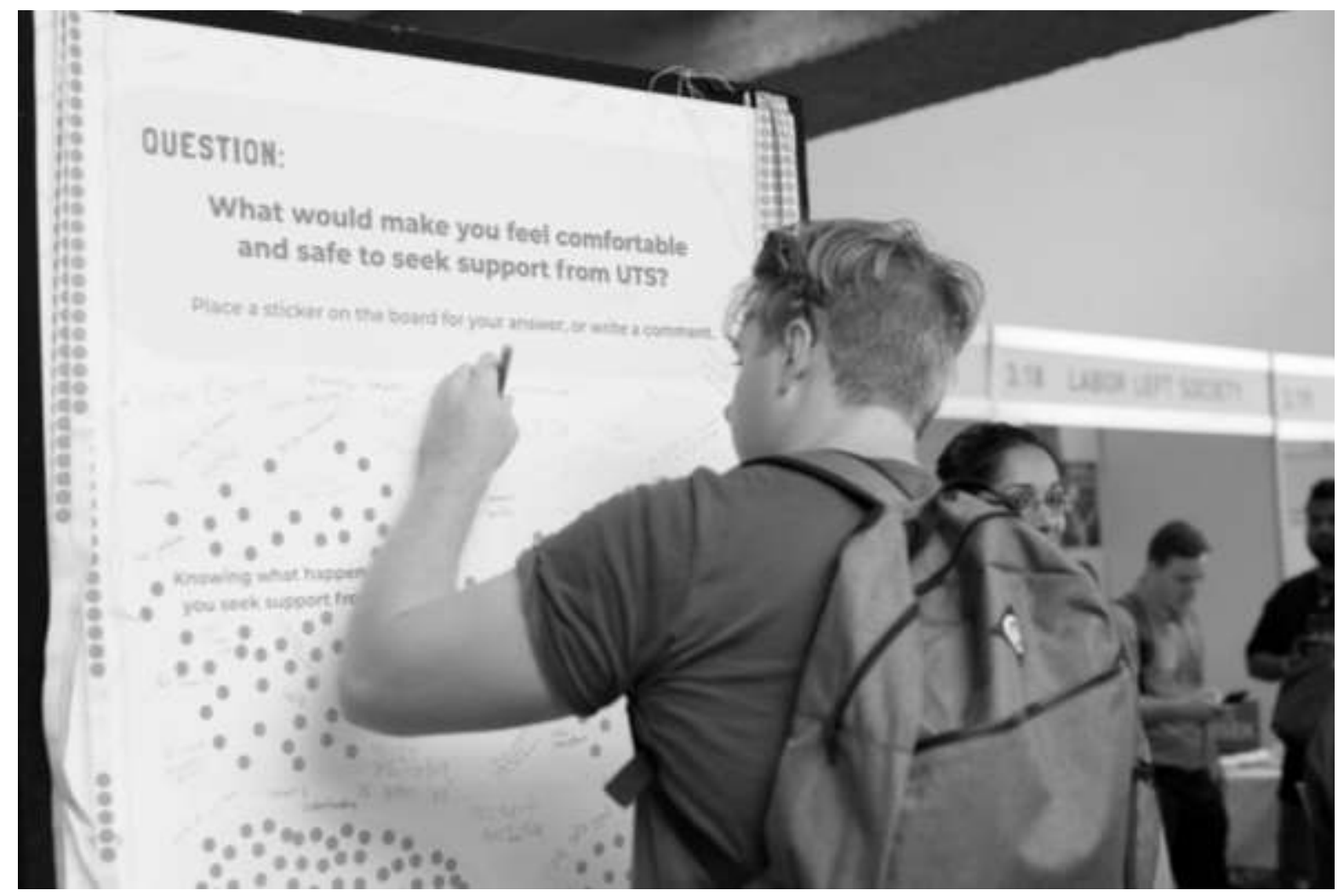

A student interacting with a question board at the O-Day ice cream stall

Many students who visited the event stalls contributed to these questions, providing further insights and data for the DIRC team to synthesise. Examples of the types of answers that students gave include (to the question 'what comes to mind when you hear the word consent?'):

"Must agree before getting freaky"

"Permission and agreement"

"Continuous communication"

"It's not a big deal to say no, teach this when we're younger"

"It's not talked about - leads to embarrassment"

"At schools teach, consensuality over sexuality"

"It's only fun if they're having fun" 


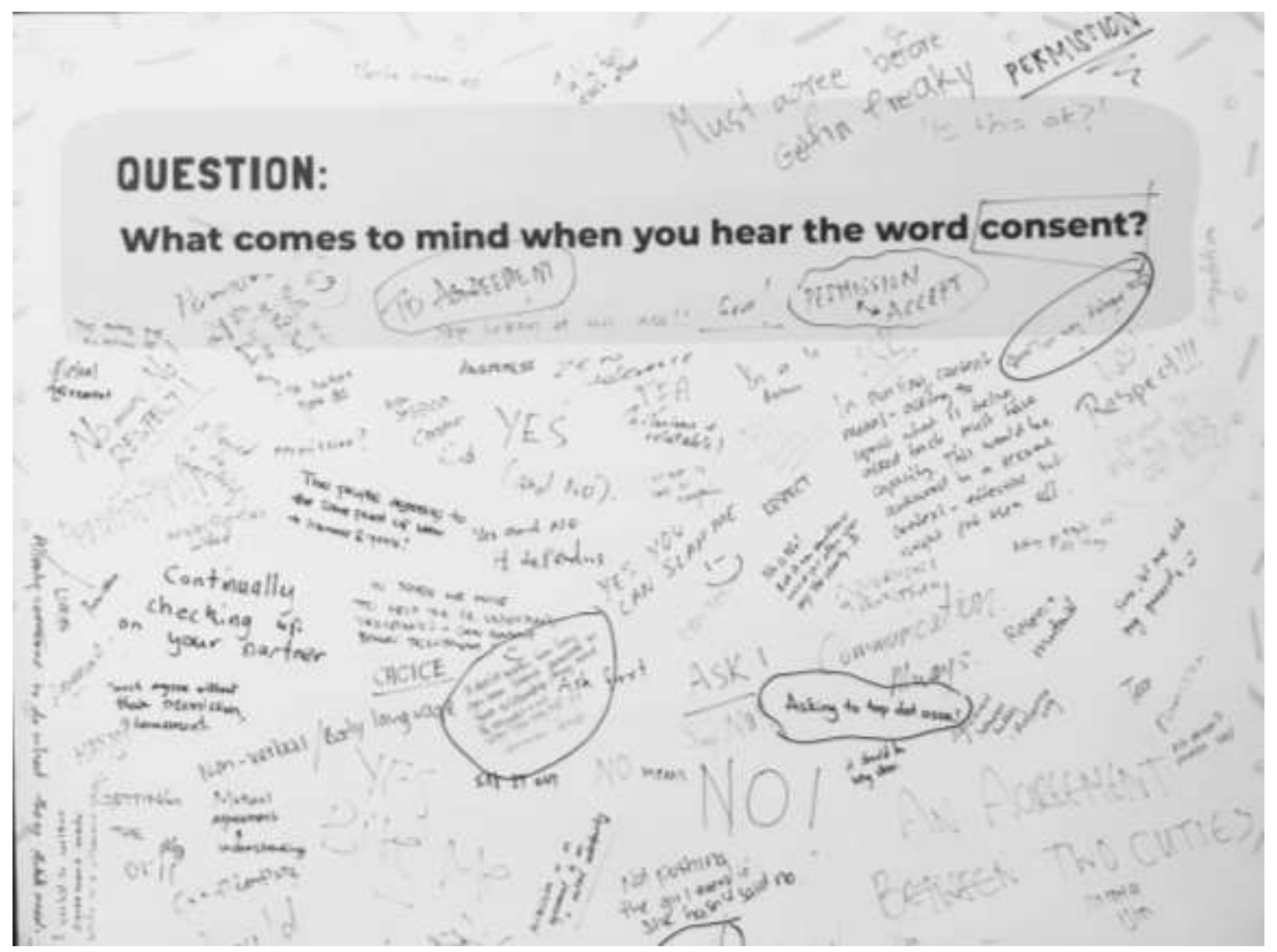

Question board from the continuing student engagement event.

\section{Implications for the University}

As a result of the insights, a list of implications for UTS was also created which provides greater direction for UTS decision makers. These implications were key in posturing us for the next body of work, intended to be more strategic and holistic. Examples of some of the implications for the university that were listed include:

- Influencing behaviour may require defining the kind of behaviour or culture change we would like to see in the UTS community.

- Reporting or support seeking is only likely when the perceived benefit outweighs the cost to the individual. This highlights the importance of efficient and targeted responses when an individual takes action.

- Services can help to address fears of reporting or support seeking by being more transparent about processes and their implications, ensuring informed choice and a sense of control.

- Since students are more likely to disclose to people they trust, student-facing staff (including casual academics) need to be prepared to provide a supportive response.

\section{Discussion}

\section{Student-University partnership}

UTS has an extensive history of student involvement in university affairs. Student representatives sit alongside professional and academic staff across a diverse range of UTS committees, working groups and boards (Governance Support Unit committees, ActivateUTS, Faculty student boards, Academic Board, etc).

The national Respect.Now.Always. campaign is high profile, and has been debated, scrutinised and criticised in the media and on campuses across Australia for over two years. The Student Voice 
research project was the first time that students were invited to work in partnership with university stakeholders to shape a local and whole-of-university UTS response.

Our desire was not to simply implement generic decisions that would attempt to eliminate sexual harassment and sexual assault on campus. Our goal was to work with UTS students from across the student cohort to better understand how they felt, develop buy-in and trust and generate targeted solutions at UTS.

While the two student representatives on the Working Group are highly valued members; it became evident that this structure of student involvement was insufficient for UTS' Respect.Now.Always program's needs. It was unreasonable to place the responsibility of forty-four thousand $(44,000)$ student views on just two people. Rather than increase the number of individuals on the committee, The Student Voice project was able to amplify the student voice with participation from across the university.

It has been recognised that while student engagement is an important solution to many institutional problems, as a concept it currently lacks clarity (Carey 2018). In order to maximise the benefits of student engagement for all stakeholders - for the university, staff, and students themselves - it is necessary to clarify what the purpose of student engagement is, and then to develop the tools and processes to achieve this. Carey (2018) places the onus of student engagement on the institution rather than on students, as institutions have the power to determine how and when students are able to engage, and how their engagement will be used.

\section{The power of design to address social challenges}

This case study highlights some of the key approaches and benefits of design that can be extrapolated for application in other social challenges and change imperatives.

\section{Treating relevance of human-centred design}

The initial brief the DIRC team received focussed on students being a key user of services and support that UTS could provide in relation to preventing sexual assault. Through this definition, they are considered a provider of data for the designer to collect and apply in the design of such services, also understood as 'designing for' (Sanders, 2003). However, as DIRC's design team began engaging with students on the issue of sexual assault and harassment, it was clear that what they had to offer included rich personal experiences and a deeper level of engagement than simply being users of a service. The design team interacted with students as active participants in the research and design, considered a participatory design or co-design approach. In this sense, stakeholders were empowered to bring ideas and take action in a design process and the designer's role was to 'design with' (Sanders 2003, Manzini 2016).

This participatory design approach is reliant on two-way dialogue, as it involves a willingness and ability to listen and understand other perspectives (Manzini 2016). We believe that the nature of this dialogue is what resonated deeply with students and may lead to cultural changes when an individual can make their beliefs and assumptions explicit, discuss these with another person and reconsider their position and behaviour in relation to this consent and navigating issues of sexual harassment or assault. In a university environment when the nature of the service experience is reliant on interpersonal relationships, constructive dialogue can also act to reduce distancing hierarchies and strengthen the social fabric of the community (Cipolla and Manzini 2009). We heard comments from students in the engagements such as "the uni isn't a voice of authority here, but of interest, inquiry", "Just come down to our level and talk to us" and "this data is coming from a place of love". In this way, a research approach developed a dual purpose of becoming a community engagement approach, building trust and constructive partnerships as it unfolded. 


\section{Design framing}

Another very powerful approach of design is that of framing, the ability to inquire into a broad problem situation rather than consider isolated problems and to form a perspective to make sense and act upon the situation (Dorst 2015, Schon \& Rein 1996). Framing is said to help designers find the 'problem behind the problem' and come up with unique solutions that wouldn't have otherwise been considered (Dorst \& Tomkin 2011). Design framing and re-framing (where problems are shown in a new light) occurred in a number of ways throughout the project.

Firstly, this occurred in the reframing of students from being considered users being researched, to being considered human participants with perspectives that validated in-person conversations between others within the UTS community (including staff volunteers in our participatory research engagements). The designers introduced this shift gradually, through re-designing research questions to be highly engaging, adjusting research questions based on topics that had resonated with the students, inviting staff volunteers to participate in the research engagements and paying careful attention to understanding and reporting on the depths of the 'student voice' that was heard. In the later engagement, self-nominating student volunteers were invited to participate in the research collection. Future engagements will be built around an even greater empowerment of students in the program thorough their involvement in the design and implementation of next engagements.

The branding of the campaign also reframed the issue of gaining consent from one surrounded in taboo, to one that was playful and approachable. By constructing a new way to perceive this issue, the design team was able to generate novelty and a spike in energy around the public engagement of this topic. We heard comments from staff and students participating in the engagement such as "this [the activation and ice-cream branding] is really weird but that's what makes it engaging, keep it novel", "It's good to approach problems in a fun way, no one like listening to talks", and "At my uni [in the US] we got free brochures, here we get free ice-cream!".

The design team also came up with an important reframe around the topic of consent, which is considered a key insight from the project. This highlights that 'sexual assault and sexual harassment is a symptom of power imbalance', a factor we believe was underlying many of the student experiences we heard about through the research. Reframing is important because in changing the way you think about a problem, a whole new pathway of solutions becomes possible (Dorst 2015). In this way, we can generate new possible pathways by considering 'what if we approached sexual assault and harassment not as a problem of consent but as a symptom of power imbalance?'. 


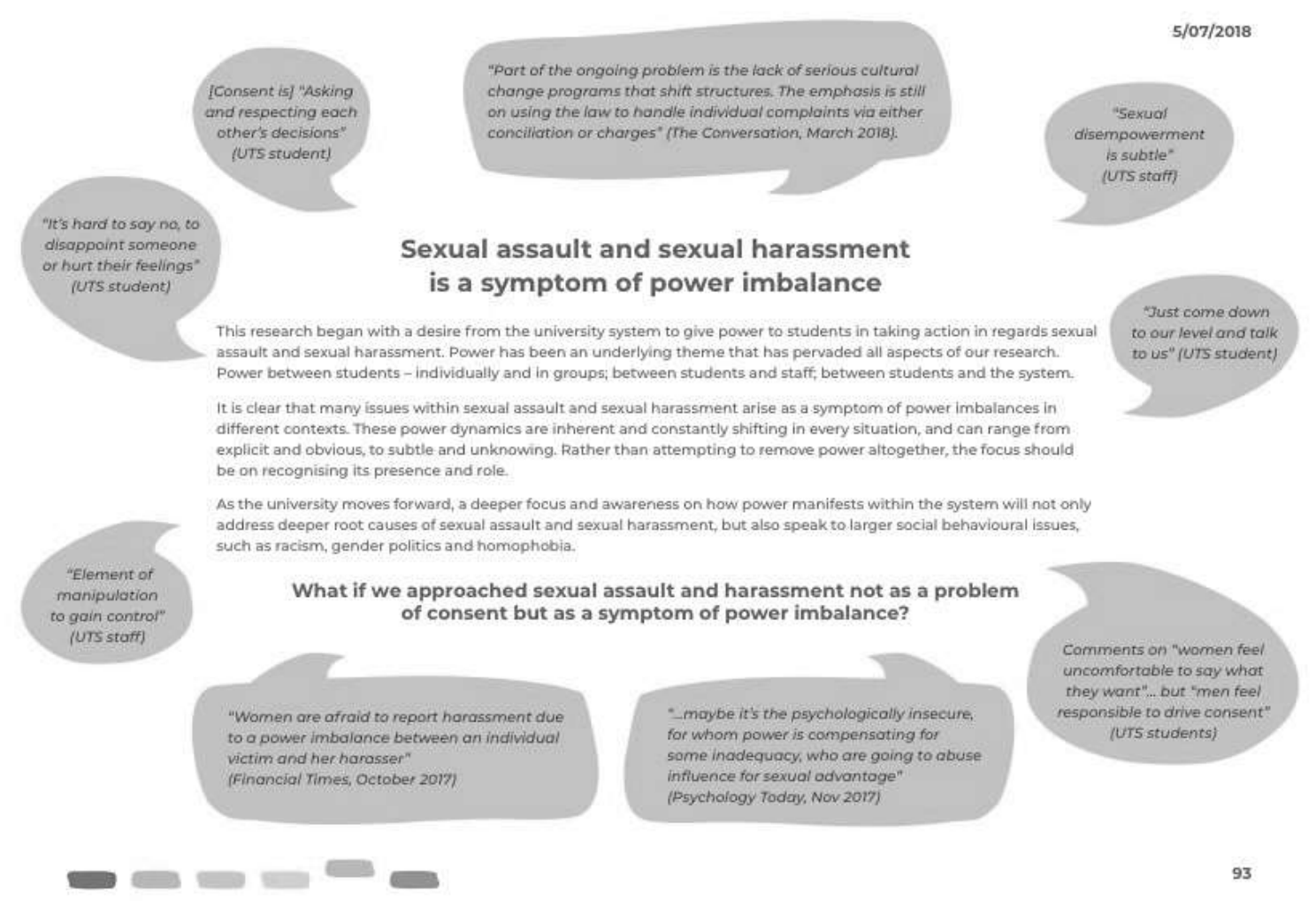

A description of the insight reframing the issue of consent to a symptom of power imbalance.

\section{Conclusion}

Fundamental to the success of this next stage of work will be the growth and strength of our relationships both within and outside the UTS community.

At the highest level, the Student Voice work to date has both confirmed and challenged assumptions with regard to UTS students' views. Our students have told us that they want to be involved and they value and expect the University to play an active role in the Respect.Now.Always. campaign. They value the effort of engaging them and they respond accordingly. Our students want straight talk, they want honesty and they want to be included in this work. They do not want generic solutions and they are impatient for the pace of change.

With the marketisation of higher education in Australia since the 1990's, students are increasingly treated and behaving like consumers rather than learners. Students are demanding more from universities than before, with an increasing shift in power moving from the provider to consumer. These two perspectives - student-as-consumer and student-as-learner - are at times contradictory and present a challenge for UTS.

How we continue to work with our student leaders, engage the cohorts and demonstrate authentic student-university partnership during periods of conflict and disagreement will require concerted planning and collaboration. We must be cognisant of the priorities and commitments of our students, and supportive of their growth. As students' appetite and expectation for university collaboration increases, we might see more public demonstrations of dissatisfaction from student leaders. It is unrealistic to assume that these often-nascent student-university partnerships will operate within the parameters set by the university. Finding opportunities and methods to buttress professional relationship capacity building for our students and staff will strengthen their contribution at university and beyond. 


\section{References}

Australian Human Rights Commission (2017). Change the course: National report on sexual assault and sexual harassment at Australian universities 2017. Sydney. https://www.humanrights.gov.au/our-work/sexdiscrimination/publications/change-course-national-report-sexual-assault-and-sexual

Baldwin, Gabrielle \& James, Richard (2000). The market in Australian higher education and the concept of student as informed consumer. Journal of Higher Education Policy and Management, (22)2, 139-148. https://www.tandfonline.com/doi/abs/10.1080/713678146

Bason, M. (2014). Design for policy. Gower Publishing Ltd.

Bunce, Louise; Baird, Amy \& Jones, Sian E. (2017) The student-as-consumer approach in higher education and its effects on academic performance. Studies in Higher Education, (42)11, 1958-1978. https://www.tandfonline.com/doi/full/10.1080/03075079.2015.1127908

Carey, P. (2018). The impact of institutional culture, policy and process on student engagement in university decisionmaking. Perspectives: Policy and Practice in Higher Education, (22)1, 11-18. https://www.tandfonline.com/doi/abs/10.1080/13603108.2016.1168754

Cipolla, C \& Manzini, E. (2009). Relational services. Knowledge, Technology \& Policy, (22), 45-50.

Dorst, K. (2015). Frame innovation; Create new thinking by design. Cambridge, MA: The MIT Press.

Dorst, K. \& Tomkin, D. (2011). Themes as bridges between problem and solution. Proceedings of the IASDR conference.

Manzini, E. (2016). Design culture and dialogic design. Design Issues 2016 (32), 52-59. https://doi.org/10.1162/DESI_a_00364

Sanders, E. (2003). From user-centred to participatory design approaches. In J.Frascara (Ed.), Design and the social sciences. Taylor \& Francis Books Limited. https://oi.org/10.1201/9780203301302

Schon, D \& Rein, M. (1996). Frame reflection. New York, NY: Basic Books.

van der Bijl - Brouwer, M., \& Dorst, K. (2017). Advancing the strategic impact of human-centred design. Design Studies, 53(2017), 1-23. https://www.sciencedirect.com/science/article/pii/S0142694X17300455?via\%3Dihub

The authors may be contacted via:

domenic.svejkar@uts.edu.au

Please cite this paper as:

Elton, K., Malcolm, B., Pruscino, C. \& Svejkar, D (2019). Design for social change: Harnessing the student voice to prevent sexual assault and sexual harassment. Journal of the Australian and New Zealand Student Services Association, 27(1), 29-44. doi.org.10.30688/janzssa.2019.04 